\title{
EXPERIENTIAL LEARNING WITH SANSAR PLATFORM - A CONCEPT OF MILITARY TRAINING
}

\author{
Małgorzata Gawlik-Kobylińska and Paweł Maciejewski \\ War Studies University \\ ul. Chrusciela 103, 00-910 Warsaw, Poland
}

\begin{abstract}
The aim of this paper is to introduce a concept of military training using a three-dimensional platform, known as Sansar. This is an extensive virtual world that users can access via accessories. We propose basic assumptions, instructional design approach, and a training concept design for consideration as an additional voice in discussions on reliable virtual military training solutions. We also stress that performing dangerous tasks with simulations and gamified activities provide opportunities for experiential learning, which takes place in a completely safe, virtual environment. The paper concluded that hypothetical situations in scenarios based on four dimensions of learning will be beneficial for learners, teachers, and institutions organizing such trainings.
\end{abstract}

\section{KEYWORDS}

Sansar, Experiential Learning, Security And Safety, CBRN+E training, Military Training

\section{INTRODUCTION}

The emergence and accessibility of state-of-the-art virtual platforms encourage teachers to use them in didactic processes (Liagkou, Stylios, 2019; Lawrence, Ahmed 2018; Melchor-Couto, 2019). This paper proposes a concept of military training that incorporates a three-dimensional (3D) virtual platform, Sansar, in a didactic process; it assumes that the application of this environment in virtual military exercises will bring huge benefits to learners, teachers and institutions organizing such trainings. Sansar, or Project Sansar, is a host for user-created virtual experiences developed by Linden Lab (Perry, 2015). It can be described as a screen-based simulation (Bastung et al., 2017) or a metaverse, a collective virtual shared space that users can access via virtual (VR) reality headsets, VR body trackers, PCs and mobile phones (Mc Adory, 2015; Baker, 2016; Sansar website, 2019). It must be mentioned that Sansar inherits the idea of "the world by residents" from Second Life, a free online virtual world platform, but due to its highly realistic computer-generated imagery, the possibility of entering it with VR accessories, Sansar, together with another similar platform, High Fidelity, exceed the affordances of Second Life (Kwon, Hudson-Smith, 2018. However, it was noted that exercises in full immersion may cause short-time side effects, such as motion sickness, disorientation, and nausea. Headsets with higher refresh rates, increased resolution and proper game designs are recommended to reduce the effects (Liagkou, Stylios, 2019).

Sansar offers the possibility of creating realistic locations or fantastic places. The designed content can be explored and published by its users. Other possibilities such as movements, voice chat, and facial animations allow for the designing of tasks based on experiencing hypothetical situations in real-life scenarios. The functionalities and application of accessories, create opportunities for experiential learning tasks, since people learn best through experience (Kolb, 2014). In military environments, experiential learning can apply to simulations (Miller et al. 2008) and games (Guillén-Nieto, Aleson-Carbonell, 2012) used to teach specific behaviours and procedures.

The introduced proposal views Sansar platform as a tool for performing specific didactic activities related to chemical, biological, nuclear, radiological, and explosive (CBRN+E) defence training. The increasing number of reports in literature on the ability to learn from one's own mistakes in a simulated environment 
underlies the concept of creating a virtual island for CBRN+E defence training (Nedic et al. 2003; Klein, 2009; Konak et al. 2014; Lowe \& Faniglione, 2016). The paper contributes to the review of open-source virtual platforms to be used in training.

\section{VIRTUAL ISLAND IN CBRN+E TRAINING}

\subsection{Basic Assumptions}

We propose to create a multifunctional virtual island in a $3 \mathrm{D}$ environment (Sansar) for CBRN+E training. A wide range of Sansar platform functionalities can be used for designing game-based exercises and simulations relevant for first responders training. The motivation for designing and using such an island is connected with the need to create a safe environment for exercises that are usually performed in a contaminated environment (behaviours before and after $\mathrm{CBRN}+\mathrm{E}$ incidents). Safe environment refers to the performance of tasks without the risk of death or serious injury. This 3D platform allows for the creation of specific sites depicting dangerous places. What is more, training conditions that are not possible to recreate in real life can be easily created in the virtual world.

Virtualization does not replace traditional training, but it is a complementary element (blended form of training). In essence, virtualization reduces to the minimum "auxiliary activities" related to the design of a virtual hostile field for training. Learners (those performing activities in a virtual island) would be familiarized with issues such as preparedness against any disaster, contamination avoidance, CBRN mitigation, knowledge on characteristics and effects of chemical and biological agents, radiological material, and nuclear weapons (Maciejewski, 2017). In most of these topics, the scenarios will involve things that can harm human health and life environmental factors. The applied games and simulations will provide opportunities to acquire competences that are significant for first responders from the field of $\mathrm{CBRN}+\mathrm{E}$ defence. Learning from their own mistakes without real-life consequences underlies the training concept assumptions.

\subsection{Instructional Design Approach}

Since the design of educational activities in the virtual environment is challenging, a four-dimensional instructional design (4D ID) approach is proposed for military training (Gawlik-Kobylińska, 2016, 2018). In this approach, the cognitive, emotional, social and psychomotor dimensions of learning are taken in consideration. The cognitive dimension concerns the design that specifically facilitates memorizing and processing of information; the emotional dimension concentrates on arousing positive emotions, attitudes and motivations, while the social dimension involves interactions between individuals and their social environments (cf. Illeris, 2003). Lastly, the psychomotor dimension focuses on the design of kinesthetic activities (e.g. Kinect technology), which are important for memorizing military drills (muscular memory) and exercising procedures. Balancing all dimensions in the scenario design is aimed at achieving better learners' performance (Gawlik-Kobylińska, 2018).

\subsection{Training Concept Design}

The target group consists of soldiers and officers who serve as CBRN+E first responders. It should be noted that the activities they perform in a virtual environment will concern selected issues from the area of $\mathrm{CBRN}+\mathrm{E}$ defence, specifically chemical and radiological (CR) incidents response as they are easier for realization in VR environment. The participants in the training will play the avatar. They will perform exercises individually and as a team, in a synchronous mode, under the supervision of an instructor. Due to the fact that this type of training is usually performed in small groups, transferring a part of learning activities to the virtual environment and managing it should not be burdensome for a teacher. Within gaming and simulation activities, single learning experiences can be of a great value as they can be used to assess the performance of an individual. A virtual performance could be recorded for further discussion in a small group. Recorded actions can also be reused in other activities (Thomas, Schneider, 2017, Sicilia, Sanchez-Alonso, n.d., Harwood, 2016). 
All learning activities can be supported with additional tools, for instance e-learning platform, which will provide the opportunity for asynchronous learning (self-education): it could be a specialized forum, multimedia materials, tutorials, e-learning courses, etc. Apart from the basic training island, other facilities can be developed, e.g. a library, cinema - display of training videos, and a conference room for the purpose of instructions, briefings, and seminars. An immediate feedback from teachers and systemic messages on learning progress will increase the self-awareness and commitment of learners (Sharmanska \& Quadrianto, 2016; Fardinpour et al., 2017).

Due to rapid development and easier access to new technologies, the concept of training could be based on the integration of a virtual platform (Sansar) with smart accessories such as VR goggles, instruments for sampling, contamination measurement, and specialist equipment handling.

\section{CONCLUSION}

Sansar platform, with its functionalities and the possibility of full immersion through the use of accessories, has prospects in military training, especially training tasks that are related to dangerous situations. Learning through experience is reinforced with the use of simulations and gaming activities involving a hazardous environment. The advantages of the concept encompass the perspectives of learners, teachers, and institutions.

For learners, the virtual military island on Sansar platform provides experiential learning in safe training conditions, which can be performed anytime and anywhere, regardless of the weather condition or distance. Additionally, the application of the 4D ID approach to the scenario design process is to maintain greater motivation and engagement in the tasks among learners.

For teachers, it provides the possibility of teaching multinational groups and tracing of learning progress by recording activities. Due to the rapid development of new technologies as well as the versatility and modifiability of the virtual environment, Sansar can be a universal platform for the implementation of a wide range of military training activities, ranging from tactics to experimental laboratories for investigations after CBRN+E incidents (rapid virtualization of a contaminated site with depiction of loss) and the possibility of implementing non-invasive chemical experiments.

The benefits for institutions are connected with lower costs of preparation of on-site incident, which is related to a significant reduction in the overall cost of training. Sansar, as an open source tool, can be used by groups of military learners from different locations, and such a course may benefit a greater number of individuals. This can lead to greater international cooperation in crisis response situation trainings. Also, if required, the training island can be available only to authorized users, with access zone control.

It should be noted that when the training program is used, it would be appropriate that soldiers and officers value the experience. At the same time, a feedback should be provided by teachers (didactic challenges, teaching preferences) and decision-makers (overall assessment, which includes, among others, cost of the training and its effectiveness).

The limitations of the concept primarily concerns the technical aspects, as in some developing countries, access to teleinformatics infrastructure could be a hindrance. Also, the software may not allow for depicting all elements and military equipment; moreover, not all experiments based on the laws of physics can be executed. Regarding psychological and social limitations of such training, it is necessary to mention the learners' preferences regarding the use of such tools. Learners and teachers also may encounter technical barriers that discourage them from using VR tools.

The increasing use of virtual reality in various aspects of human activity generates an increasing demand for research in the field of potential use of new technologies, especially for security and defence purposes. The concept will be highly useful in developing innovative trainings in the field of education for security and defence. It will also contribute to the analyses of the virtual world's didactic potential. 


\section{REFERENCES}

Barker, V. E. 2016. Flow in virtual worlds: The interplay of community and site features as predictors of involvement. Journal for Virtual Worlds Research, 9(3).

Bastug, E., Bennis, M., Médard, M., \& Debbah, M. 2017. Toward interconnected virtual reality: Opportunities, challenges, and enablers. IEEE Communications Magazine, 55(6), pp. 110-117.

Fardinpour, A., Reiners, T., \& Wood, L. C. 2017. Action-based learning assessment in virtual training environments. Authentic Virtual World Education, pp. 79-94. doi:10.1007/978-981-10-6382-4_6

Gawlik-Kobylińska, M. 2018. The Four-Dimensional Instructional Design Approach in the Perspective of Human-Computer Interactions. In Applications of Intelligent Systems: Proceedings of the 1st International APPIS Conference 2018 (Vol. 310, p. 146). IOS Press.

Gawlik-Kobylińska, M. 2016, Cztery wymiary uczenia się w projektowaniu scenariusza kursu e-learning owego, Zeszyty Naukowe Akademii Obrony Narodowej, 105(4), pp.39-52.

Guillén-Nieto, V., \& Aleson-Carbonell, M. 2012. Serious games and learning effectiveness: The case of It's a Deal!. Computers \& Education, 58(1), pp. 435-448.

Harwood, T. 2016. Co-curated Digital Culture: Machinima. Leonardo. MIT Press Journal, Massachusetts, USA.

Illeris, K. 2003. Towards a contemporary and comprehensive theory of learning. International Journal of Lifelong Education, 22, pp. 396-406.

Klein, R. 2009. Learning from Others and Learning from Mistakes Reflections on Health Policy Making. Comparative Studies and the Politics of Modern Medical Care, pp. 305-318.

Kolb, D. A. 2014. Experiential learning: Experience as the source of learning and development. FT press, New Jersey, USA.

Konak, A., Clark, T. K., \& Nasereddin, M. 2014. Using Kolb's Experiential Learning Cycle to improve student learning in virtual computer laboratories. Computers \& Education, 72, pp. 11-22.

Kwon, H; Hudson-Smith, AP. 2018. Redesigning Experience Consumption in Social VR Worlds: Decentralised Value Creation, Mobilisation, and Exchanges. In Proceedings of the Academic Design Management Conference: Next Wave ADMC18. (pp. 269-278). DMI: Ravensbourne University, London, UK

Lawrence, G., \& Ahmed, F. 2018. Pedagogical Insights into Hyper-Immersive Virtual World Language Learning Environments. International Journal of Computer-Assisted Language Learning and Teaching (IJCALLT), 8(1), pp. 1-14.

Liagkou, V., \& Stylios, C. 2019. A Case Study of a Virtual Training Environment. In Advances in Manufacturing II, pp. 352-367. Springer, Cham.

Lowe, G., \& Faniglione, D. 2016. Virtual Training for the Development of Real World Skills. ICERI 2016 Proceedings.

Maciejewski, P. 2017. ICT tools in CBRN troops' education and training. Zeszyty Naukowe/Wyższa Szkoła Oficerska Wojsk Lądowych im. gen. T. Kościuszki, 49(4), pp. 121-137.

Melchor-Couto, S. 2019. Virtual worlds and language learning. Journal of Gaming \& Virtual Worlds, 11(1), pp. 29-43.

McAdory, P. 2015, August 20. Second Life developer invites first creators to next-gen made-forVR virtual world [blog post]. Retrieved from http://www.roadtovr.com/second-life-developerinvites-first-creators-to-next-gen-made-for-vrvirtual-world/

Miller, K. K., Riley, W., Davis, S., \& Hansen, H. E. (2008). In situ simulation: a method of experiential learning to promote safety and team behavior. The Journal of perinatal \& neonatal nursing, 22(2), pp. 105-113.

Nedic, Z., Machotka, J., \& Nafalski, A. 2003. Remote laboratories versus virtual and real laboratories. IEEE.33rd Annual Frontiers in Education, Vol. 1, pp. T3E-T3E).

Perry, T. S. 2015. Virtual reality goes social. IEEE Spectrum, 53(1), pp. 56-57.

Sansar website. 2019, June 11.Sansar compatibility FAQ. Retrieved from https:/help.sansar.com/hc/enus/articles/360027483852-Sansar-compatibility-FAQ.

Sharmanska, V., \& Quadrianto, N. 2016. Learning from the Mistakes of Others: Matching Errors in Cross-Dataset Learning. 2016 IEEE Conference on Computer Vision and Pattern Recognition (CVPR).

Sicilia, M.-A., \& Sanchez-Alonso, E. n.d. Reusable Learning Resources for Virtual Learning Environments. Encyclopedia of Virtual Communities and Technologies.

Thomas, M. \& Schneider, C. 2017. Language Learning with Machinima: Video Production in 3D Immersive Environments. In: Teaching English reflectively with technology. IATEFL, Canterbury, UK. 